\title{
El discurso de la ciencia para chicos, o la explicación como diálogo. Un análisis polifónico-argumentativo de libros de divulgación científica infantil en español
}

\author{
O discurso da ciência para as crianças, ou explicação como o diálogo. \\ Uma análise argumentativa-polifônico de livros de divulgação científica para crianças em español \\ The discourse of science for children, or explanation as dialogue. \\ A polyphonic-argumentative analysis of popular science books for children in spanish
}

\section{Carolina Tosi}

Consejo Nacional de Investigaciones Científicas y Técnicas, Universidad de Buenos Aires - Buenos Aires - Argentina

$$
\diamond
$$

Resumen: El presente artículo aborda un género hasta ahora poco explorado: los libros de divulgación científica para niños. A la luz de la teoría polifónica de la enunciación de Ducrot (1984), y en un corpus de libros escritos en español, editados en la Argentina (2000-2015), se caracterizan los mecanismos microdiscursivos que exhiben la dimensión polifónica y argumentativa de este tipo de discurso. Debido a que el género bajo análisis se configura a partir de la exhibición explícita de un supuesto diálogo con el lector, se indaga especialmente el lazo discursivo que se establece entre locutor y destinatario dentro de tal imaginario de interlocución. Entre los procedimientos microdiscursivos más usuales para configurar el diálogo explícito, se analizan, además de las desinencias verbales y los pronombres en segunda persona del singular, las preguntas con apelación directa al destinatario y las marcas de coloquialidad, las construcciones concesivas y las proposiciones condicionales.

Palabras clave: Divulgación científica; Niños; Polifonía; Argumentación

Resumo: Este artigo discute um gênero até então inexplorados: os livros de ciência para crianças. À luz da teoria polifônica da enunciação de Ducrot (1984), e um corpus de livros escritos em espanhol, publicado na Argentina (2000-2015), os mecanismos microdiscursivos exibindo dimensão polifônica e argumentativa desse recurso tipo de discurso. Porque a análise de gênero é definido baixo do visor explícita de um suposto diálogo com o leitor, especialmente explora o vínculo discursivo estabelecida entre alto-falante e destinatário no diálogo imaginário. Entre os mais comuns para definir procedimentos explícitos microdiscursivos diálogo, para além das terminações verbais e pronomes na segunda pessoa do singular, que discutiu as questões com o destinatário e outras marcas de recurso coloquial, construções concessivo e instruções condicionais.

Palavras-chave: Popular science; Crianças; Polifonia; Argumento

\begin{abstract}
This article discusses a genre hitherto unexplored: the science books for children. In light of the Polyphonic Theory of Enunciation of Ducrot (1984), and a corpus of books written in Spanish, published in Argentina (2000-2015), the mechanisms microdiscursivos exhibiting polyphonic and argumentative dimension of this feature type of discourse. Because gender analysis is set low from the explicit display of a supposed dialogue with the reader, especially explores the discursive bond established between speaker and addressee within the imaginary dialogue. Among the most common to set explicit dialogue microdiscursivos procedures, in addition to the verb endings and pronouns in the second person singular, they discussed the questions with the recipient and other brands of colloquial appeal, concessive constructions and conditional statements.
\end{abstract}

Keywords: Popular science; Children; Polyphony; Argument 


\section{Introducción}

Dentro del marco del Análisis del Discurso, la divulgación científica puede definirse como el proceso de recontextualización de un conocimiento generado en ámbitos especializados -cuya producción y comunicación se establece entre científicos- en una situación comunicativa nueva, destinada a un público masivo y lego (CALSAMIGLIA, 1997 y CASSANY, 1998). La actividad divulgadora consiste, así, en la recreación del conocimiento para una audiencia diferente y que, por ende, exige la elaboración de formas discursivas acordes con las nuevas circunstancias. No obstante, lejos de concebirse como un campo homogéneo que presenta rasgos situacionales y lingüísticos comunes, generalizables a todas las manifestaciones textuales (CIAPUSCIO, 1992, 2000 y 2013), la divulgación de la ciencia "constituye un dominio heterogéneo que abarca una multiplicidad de géneros discursivos, diferentes emisores (científicos, periodísticos y divulgadores formados en disciplinas muy diversas) y distintos soportes (gráficos, audiovisuales)" (GALLARDO, 2013, p. 57). Desde tal perspectiva, cada género de la divulgación de la ciencia manifiesta rasgos lingüísticos particulares, especialmente en los niveles superestructural, gramatical y lexical. Pero además, y como se intentará demostrar en esta oportunidad, existen procedimientos microdiscursivos que caracterizan los géneros, a la vez que evidencian la dimensión polifónicoargumentativa del discurso y vehiculizan determinados "efectos de sentido" (ORLANDI, 2003, p. 63) 1 .

A partir del referido encuadre, el presente artículo analiza un género específico de la divulgación científica: "los libros de divulgación científica para chicos", editados en la Argentina entre 2000 y 2015. A la luz de la teoría polifónica de la enunciación de Ducrot [1984] (2001) y, en el marco de los estudios del "Enfoque Dialógico de la Argumentación y de la Polifonía" (EDAP), dirigido por la Dra. García Negroni en la Universidad de Buenos Aires (Argentina), se caracterizan algunas estrategias polifónico-argumentativas que configuran al locutor y al destinatario. Vale a aclarar que, debido a que se trata de un tipo genérico que se construye a partir de la exhibición explícita de un supuesto diálogo con el lector, el foco de abordaje se colocará especialmente en el lazo discursivo que se establece entre locutor y destinatario dentro del imaginario de interlocución, lo que a su vez repercute en la configuración del ethos -entendido

\footnotetext{
1 En trabajos anteriores (TOSI, 2015a y 2015b), hemos analizado algunas formulaciones características de los libros de la divulgación científica para chicos que materializan diferentes tipos de posicionamiento de locutor-autor ante el saber de la doxa, como la negación metadiscursiva (GARCÍA NEGRONI, 2009), preguntas con respuestas doxales implícitas y marcador discursivo "en realidad", entre otros.
}

este como la construcción de la imagen que realiza el locutor de sí mismo en el discurso a través del uso de recursos lingüísticos (AMOSSY, 1999, p. 2)- y de una determinada representación de ciencia.

Se estima que el género bajo análisis posee relevancia para los estudios lingüísticos, puesto que pone en escena la transmisión y circulación de conocimientos en el ámbito de la comunicación pública de la ciencia destinada a un público particular: los niños y adolescentes. Por otra parte, se deja sentado que existen escasas investigaciones que se hayan ocupado de dicho objeto de estudio (VALLEJOS y PALMUCCI, 2010 y 2011). Por ello, se consideran necesarios nuevos abordajes que se lleven a cabo desde diferentes perspectivas como, por ejemplo, en este caso, desde el enfoque enunciativo. Asimismo, con la presente investigación se aspira a contribuir al conocimiento de la cultura escrita de la ciencia destinada para chicos, mediante la indagación de las estrategias desplegadas en las diferentes propuestas editoriales.

A continuación, exponemos el marco teórico de referencia, caracterizamos nuestro objeto de estudio y explicamos la configuración del corpus (§ 2 y 3 ). Luego, damos cuenta de ciertos aspectos enunciativos vinculados con el dialogismo y la subjetividad en la ciencia (§ 4) y presentamos el análisis discursivo ( $\$ 5)$. Para finalizar, exhibimos las conclusiones a las que arribamos $(\S 6)$.

\section{Algunas consideraciones teóricas}

Nuestro marco teórico lo constituye la teoría polifónica de la enunciación de Ducrot [1984] (2001) que, sobre la base de las nociones de enunciación y subjetividad propuestas por Benveniste (1966), y los conceptos de dialogismo y polifonía de Bajtín (1976 y 1982), plantea la subjetividad como un rasgo constitutivo de la lengua, y los discursos, como productos de una multiplicidad de voces con una determinada orientación argumentativa. Como lo explica García Negroni (2011, p. 17): “en la medida en que los puntos de vista vehiculizados en el enunciado evocan otras voces y orientan hacia ciertos discursos, alejándolos de otros, el lenguaje es también básicamente dialógico".

Vale destacar que la polifonía remite, en el plano lingüístico, a una pluralidad de puntos de vista representados en el enunciado, frente a los cuales el locutor adopta una determinada postura. Ducrot (1984) distingue el sujeto empírico (SE), en tanto autor efectivo y productor del enunciado, de una serie de voces que se aparecen en los distintos niveles del enunciado. Entre esta pluralidad de voces, que son instancia puramente discursivas, distingue al locutor como tal (L), fuente y responsable de la enunciación (no necesariamente identificable con $\mathrm{SE}$ ), al locutor como ser del mundo (locutor $\lambda$ ), origen 
del enunciado y objeto de su enunciación (aquel que dice "yo"), i. e. un personaje que puede tener adjudicadas otras propiedades ajenas a sí, y finalmente a los enunciadores (E1, E2) entendidos estos como distintos puntos de vista presentes en el enunciado.

Con respecto a los enunciadores, estos pueden ser caracterizados como puntos de vista que se ubican en un nivel diferente de $\mathrm{L}$, puesto que se trata de las distintas representaciones que ocurren en la enunciación. Así planteado, es posible que los enunciadores se asimilen a personas diferentes de L y este, a su vez, pueda tener actitudes diversas con relación a ellos, ya sea de identificación, asimilación, acuerdo u oposición. El locutor (L), entonces, puede adoptar diferentes posiciones y mostrarse, en su compromiso enunciativo, envestido de ciertas cualidades que hacen más aceptable su enunciación y contribuyen a modelar un determinado ethos discursivo ${ }^{2}$ y también proyecta una imagen de destinatario que se configura como coconstructor de su enunciado ${ }^{3}$. Si bien, según la concepción bajtiniana del lenguaje, retomada por la teoría polifónica de la enunciación, todo discurso se construye en relación con otros discursos, en el presente trabajo nos centramos en abordar la dimensión dialógica explícita de la divulgación científica, es decir aquella puesta en escena por parte del "locutor-autor", a partir de la cual organiza su discurso y modela a su "destinatariolector".

\section{La constitución del corpus}

El mercado de los libros de divulgación científica para niños en la Argentina surge aproximadamente en 2001, dentro de un contexto social conflictivo, signado por la profunda crisis económica que atravesó el país desde fines de ese año. Como es sabido, dicha crisis -entre otras nefastas consecuencias- produjo el resquebrajamiento de la industria editorial y la recesión de gran parte del mercado. No obstante, ante este panorama desfavorable, surgieron pequeños emprendimientos editoriales independientes y autogestivos en el campo de la edición de libros con destinatario infantil y juvenil y, entre ellos, floreció el género de la divulgación científica. La editorial pionera en este rubro ha sido Iamiqué, pero posteriormente editoriales académicas de gran tradición, como Fondo de Cultura Económica, Siglo Veintiuno o Eudeba, también incursionaron en el género. Actualmente, se trata de un sector comercial que tiene una importante presencia en el mercado argentino e, incluso, sus productos se exportan a diversos países y se presentan en ferias del libro internacionales.

Para la constitución del corpus, seleccionamos 30 libros de dos editoriales que producen libros de divulgación científica -especialmente de las llamadas "ciencias duras" (Física, Química, Astronomía, etc.)-, y que pueden considerarse representativas debido a su relevancia en el mercado y porque constituyen dos modelos de empresas diferentes: Iamiqué y Eudeba. Por un lado, Iamiqué es una editorial independiente que, como ya hemos mencionado, se dedica exclusivamente a este género. Hemos seleccionado para el análisis las colecciones "Las cosas no fueron siempre así", "Asquerosología" y "Preguntas que ponen los pelos de punta". Por otro lado, Eudeba es una editorial académica que fue fundada hace 51 años y pertenece a la Universidad de Buenos Aires. En un primer momento, se trató de una editorial "del autor universitario para la universidad y para la sociedad", pero ya entrado el siglo XXI diversificó su propuesta e incursionó en la edición de libros de divulgación científica y así creo la colección “¿Querés saber?", objeto de nuestro abordaje.

Los autores de ambas propuestas editoriales son, en general académicos y especialistas en los temas que abordan (físicos, químicos, geólogos, etc.), aunque en algunos casos los textos cuentan con la adaptación autoral de especialistas en divulgación y con experiencia en escritura destinada al público infantil ${ }^{4}$. Tanto Imaiqué como Eudeba plantean productos de alta calidad, que buscan atraer al lector a partir de diferentes recursos, como los temas elegidos, la ilustración, el diseño y el tratamiento lingüístico de los textos, según mostraremos a lo largo del análisis.

Su destinatario no suele ser el alumno de colegio o el docente, ni tampoco los contenidos que desarrollan responden necesariamente a los diseños curriculares -como sí ocurre con los libros de texto-- En este sentido, al no tener que cumplir con los contenidos curriculares, los editores de divulgación disponen de una mayor libertad para seleccionar los temas y las formas de abordarlos. En líneas generales, son libros que no se adoptan para la enseñanza en los colegios, sino que se suelen adquirir en librerías por venta espontánea. No obstante, vale aclarar que, en los últimos años, este tipo de libros circula en los colegios de todo el país, debido principalmente a las compras de libros para escuelas públicas llevadas a

\footnotetext{
2 Recordemos que, para Ducrot, "el ethos está ligado a L, el locutor en tanto que tal: es porque él está en el origen de la enunciación que él se ve investido de ciertos caracteres que, por contragolpe, vuelven a esa enunciación aceptable o desechable" ([1984] 2001, p. 201).

3 Con respecto a este último aspecto, tengamos en cuenta que, para Benveniste (1966), la enunciación presenta dos figuras igualmente necesarias: una, la fuente y la otra, el destino de la enunciación, locutor y del alocutario, respectivamente, que entablan en una relación de dependencia.

4 Ese es el caso, por ejemplo, de Paula Bombara, la directora de la colección "¿Querés saber?” (Eudeba), escritora literaria y bioquímica, que es también la responsable de la adaptación de algunos de los textos. Asimismo, en la propuesta de Iamiqué es fundamental el rol de las editoras, que suelen ser Carla Baredes, física, e Ileana Lotersztain, química, ambas directoras y responsables de la editorial.
} 
cabo por el Ministerio de Educación de la Nación (TOSI, 2015a).

Para concluir este apartado, señalamos que, recurriendo al estudio cualitativo de los datos, nos hemos abocado a registrar los mecanismos desplegados para la construcción del "diálogo" entre el locutor-autor y destinatario-lector, que presentan mayor ocurrencia en nuestro corpus, según se dará cuenta en el próximo apartado. Vale indicar que cada ejemplo consta del número del libro correspondiente, tal como aparece listado al final del artículo, y del número de página de donde fue extraída la cita; el subrayado es nuestro y se utiliza para destacar algún segmento en especial, de acuerdo lo requiera el análisis.

\section{Dialogismo y subjetividad en el discurso de la ciencia}

Como es sabido, la escritura científica se caracteriza por la pretensión de objetividad y neutralidad. Para lograr tal efecto, el locutor-autor recurre a diversas estrategias de despersonalización, como nominalizaciones, estructuras impersonales con infinitivos, pasivas con se o ser, entre otras, que refuerzan la pretensión de neutralidad y diluyen la responsabilidad en tanto ocultan la fuente de la enunciación (GARCÍA NEGONI, 2008). Guiados por ese mismo fin, el discurso científico-académico también evita la apelación directa al destinatario-lector.

La divulgación científica para adultos mantiene en parte ese mismo interés por lograr un discurso desprovisto de emotividad y centrarse en los objetos cognitivos a través de una supuesta neutralidad (CIAPUSCIO, 1992). Por ello, toda referencia explícita al locutor-autor o al destinatario-lector es también diluida. No obstante, Ciapuscio sostiene que esto varía según los géneros y el público, si este es más restringido (como un artículo de una revista especializada) la pretensión de objetividad será mayor y si se trata de un público amplio (como una nota de diario) será menor. En efecto, al igual que en el discurso científico hay escasas menciones al yo y prácticamente nulas apelaciones directas al destinatario a través de formas de segunda persona -i. e. vos, usted, tú, ustedes- (CIAPUSCIO, 1992).

Finalmente, en la divulgación científica para chicos también se evita el yo, pues parece mantenerse la pretensión por mitigar las alusiones a la fuente de enunciación. Al igual que en el discurso científico y en el de la divulgación para adultos, el locutor-autor configurado en nuestro corpus suele recurrir a estrategias de despersonalización y de personalización -como el nosotros genérico e inclusivo, en los que el lector queda incorporado en el mismo grupo del autor (GARCÍA NEGRONI, 2008)-. Estos mecanismos tienen ocurrencia en la divulgación científica para niños pero, con el fin de acotar nuestro estudio, aclaramos que estos no serán objeto de análisis de este trabajo ${ }^{5}$.

Sin dudas, el recurso más evidente para la configuración del diálogo que presenta nuestro corpus lo constituyen las alusiones directas al destinatario-lector, con las que se pretende emular una interacción "real". Así, lo ilustra el siguiente ejemplo, que reproduce la página completa de uno de los libros abordados:

(1) No parece muy complicado: ves la lámpara porque su luz llega a tus ojos, ves el televisor porque la luz de la pantalla llega hasta tus ojos, ves el fuego porque la luz de las llamas llega hasta tus ojos.

Pero si este libro no tiene luz... ¿por qué lo estás viendo? Porque aunque no tiene luz propia, parte de la luz que hay a tu alrededor choca con él, rebota y viaja hasta tus ojos. Esa luz que entra en tus ojos es la que hace que veas este libro. (1:7).

Como queda claro en (1), la explicación se articula mediante rasgos dialógicos. Se apela al destinatario-lector a través de desinencias verbales ("ves", "estás", "viendo" y "veas)" y pronombres en segunda persona del singular ("tus"). Si en Eudeba predominan las formas voseantes, prototípicas del español rioplatense: "¿Te imaginás qué es?" (3:6), o "¿Serás vos quien ayude a resolver este misterio?" (8:11), en Iamiqué prevalecen las tuteantes ("Claro, no puedes verla" (5:7), o "Gracias a la luz del Sol puedes ver la Luna, los árboles, los pájaros, las montañas, las veredas, la gente que camina por la calle" (1: 4). Esta diferencia radica principalmente en un criterio comercial, pues Iamiqué contempla la exportación de libros y por eso elige la forma tuteante, que se considera de mayor uso en Hispanoamérica, territorio de venta de sus productos ${ }^{6}$.

Aunque en escasa cantidad y con menor variedad de recursos, la estructura dialógica explícita se rastrea también en el discurso pedagógico, especialmente en ciertos espacios de los libros de texto de edición reciente que cumplen el objetivo de recrear el intercambio aúlico y auxiliar tanto al alumno como al docente (CASTRO FOX Y MONTI, 2003 y TOSI, 2009). No obstante, y como ya hemos dado cuenta en un trabajo anterior, la alusión al lector en los libros de texto se produce principalmente a

\footnotetext{
5 Con el fin de indagar estas y otras formas personalizadas y despersonalizadas para la construcción del locutor-autor en los diferentes tipos de discursos, se recomienda consultar Ciapuscio (1992); Gallardo (2004) y García Negroni, (2008).

6 En el español rioplatense, la apelación al interlocutor se realiza en forma extendida en todos los estratos sociales a partir de las formas vos / usted. No obstante ello, la representación de este rasgo característico de la variedad rioplantense no suele ser positiva y generalmente es considerada como subestándar y limitada a un uso coloquial. Para ampliar la problemática del uso de voseo en textos destinados a niños, consultar García Negroni y Ramírez Gelbes (2005) y López García (2006).
} 
través de verbos en imperativo, que vehiculizan "acciones que el alumno tendría que desarrollar para llevar a cabo con éxito el aprendizaje" (TOSI, 2009, p. 106), formas estas escasas en el corpus analizado en el presente trabajo. De esta manera, el locutor-autor del libro de texto "emprende no solo una acción directiva respecto del alumno sino también del profesor, pues adopta una función propia del docente ya que determina y muestra cuáles son los conocimientos que requiere el destinatario lego y las acciones que debe realizar" (TOSI, 2009, p. 108-109).

Entre los procedimientos microdiscursivos habituales para apelar al destinatario-lector y configurar un diálogo ficticio, hemos registrado tres tipos de alta ocurrencia en nuestro corpus: las preguntas con apelación directa al destinatario-lector y otras marcas de coloquialidad ( $§ 5.1$ ); las construcciones concesivas (§ 5.2) y las proposiciones condicionales ( $§ 5.3)$, que serán caracterizados a continuación.

\section{Estrategias polifónico-argumentativas para la construcción del diálogo}

\subsection{Organizadores de la explicación. Las preguntas y las marcas de coloquialidad}

Tal cual ya hemos adelantado, el locutor-autor de los textos de divulgación para chicos recurre a la apelación directa al destinatario-lector mediante verbos y pronombres personales en segunda persona del singular como recursos nodales para montar el supuesto diálogo. Como se sabe, se trata de la mera escenificación del intercambio, puesto que en un texto escrito de tales características es imposible la respuesta real del destinatario-lector. De esta forma, el locutor-autor del texto ejecuta acciones de regulación y control discursivo ya que le asigna al lector determinados saberes y experiencias y construye así una determinada representación de él. Pero exhibir la dimensión subjetiva y dialógica del lenguaje tiene sus efectos de sentido, porque implica no solo reconocer la existencia de otros puntos de vistas, sino también jerarquizar la figura del lector y ofrecer una imagen no convencional de ciencia, como demostraremos a continuación. En efecto, al convocar, mostrar y poner en foco al destinatario-lector, quedan desplazadas en cierta manera las propiedades de objetividad y asepsia que se le suelen adjudicar a la ciencia.

Una de las estrategias más habituales para construir el efecto de diálogo es la formulación de preguntas y la inclusión de expresiones coloquiales.

Por un lado, mediante las preguntas, el locutorautor busca activar y recuperar las experiencias o los conocimientos previos del destinatario-lector, que podrían devenir de la observación cotidiana y remitir a conocimientos del sentido común (cf. 2 y 3 ), o bien del recuerdo de ciertos conceptos que ya fueron explicados en el texto mismo y que se suponen sabidos (cf. 4). Los interrogantes funcionan así como marcos para iniciar la explicación, es decir son puntos de partida para contextualizar el tema o el concepto que se busca desarrollar.

(2) ¿Viste que cualquier cosa que tires para arriba, tarde o tempano, cae? (9:23)

(3) En los días muy fríos, seguramente te divierte inspirar y soplar solo para "ver" tu aliento. ¿ $\underline{\text { Sabes qué es, en }}$ realidad? $(5: 8)$

(4) $i$ Te acuerdas de que las pelotitas que forman el aire de la Tierra desvían la luz del Sol? (1:34)

Pero además, el locutor-autor introduce preguntas que apelan a supuestas reacciones o actitudes del destinatariolector, como se observa en (5) y (6). De esta forma, notamos que ambas preguntas impregnan el discurso de cierta emotividad, pues remiten a dos emociones que no se asociarían convencionalmente al discurso aséptico de la ciencia: la sorpresa (cf. 5) y la fascinación (cf. 6). Sumado a ello, la inserción de expresiones coloquiales, como "voilá!" en (5), "qué onda” en (7) y “iojo!” en (8), tienden a amenizar la explicación, hacerla más dinámica y a emularla a los intercambios orales informales. Sin dudas, todo ello incide en suscitar el efecto de que la asimetría entre el experto y el lego se diluye, y de que la dimensión subjetiva del lenguaje emerge en la materialidad misma de la explicación para un ocupar un espacio que suele ser inusual en el discurso de la ciencia.

(5) ¿Sorprendido? En realidad, casi todas las islas océanicas son grandes volcanes que se elevaron desde el fondo marino. Voilá! (10:50).

(6) iNo te parece fascinante saber que existe todo un mundo microscópico tan grande y valioso como el que vemos a simple vista? (7:32).

(7) Es la onda sísimica. ¿Qué onda! (10:25)

(8) Enrique era de los Lancaster y Ricardo, de los York. El escudo de los Lancaster tenía una rosa roja, y el de los York, una rosa blanca. ¡Ojo! No eran dos equipos de fútbol, sino las dos familias herederas de la corona inglesa. (1:15)

Además, registramos "pseudo-preguntas" (FILINICH, 99:43), introducidas mediante “Sabías que...?”, cuya función no sería interrogar al destinatario-lector, sino introducir una concepto relevante (cf. 9 y 10). En las "pseudo-preguntas" detectamos un empleo especial del pretérito imperfecto ("sabías"). Con relación a ello, 
García Negroni (2010, p. 363) explica diversos usos y significados y, entre estos, menciona el "fático". Así lo define: "Con un valor temporal del presente se utiliza este imperfecto para señalar que se reanuda una conversación que se había interrumpido”, como por ejemplo: “Decía usted?". Como vemos en los ejemplos (cf. 9 y 10), también con un valor temporal del presente y una función fática, pero con un sentido enunciativo diferente, el "¿sabías que?" es utilizado por el locutor-autor de la divulgación científica con el fin de iniciar una explicación, o bien para destacar como relevante el concepto que introduce.

¿Sabías que no se podría vivir si no existieran las bacterias? $(7: 10)$

(10) ¿Sabías que en el aire hay agua? (5:7)

De uso habitual en los textos pedagógicos, esta expresión señala en forma solapada que el texto que la sigue es clave para el tema que se desarrolla y por ello lo anticipa: con el objetivo de que el destinatario-lector le preste especial atención. De hecho, “¿el sabías que?" podría interpretarse como una alerta, ya que intenta atraer la atención del lego y despertar su curiosidad, a la vez que remarca la importancia de la información que lo sucede.

En suma, tanto las preguntas como las expresiones coloquiales contribuyen a configurar un imaginario de diálogo y modelan, por un lado, un ethos divulgador que organiza eficazmente la explicación y se manifiesta atento a los saberes del lego y, por el otro, construye un lector que parecería participar en la construcción del conocimiento, pues en apariencia sus saberes y experiencias previas son tenidas en cuenta.

\subsection{La introducción de marcos enunciativos. Las construcciones concesivas}

Desde la perspectiva polifónica, la construcción concesiva presenta el punto de vista de un enunciador del que el locutor-autor se distancia; sin embargo, no lo refuta, sino que lo incorpora en su discurso con el fin de introducir otro punto de vista con el cual sí se identifica. De esta manera, el locutor-autor argumenta a favor de la conclusión contraria a la que debería conducir el punto de vista manifiesto en el segmento concesivo. En este sentido, de acuerdo con Ducrot y Anscombre (1984), al utilizar un enunciado concesivo encabezado por aunque el locutor-autor permite en un primer momento que se argumente en la dirección opuesta a la conclusión a la que desea arribar. Como lo explican ambos autores, a través de la concesión, el locutor-autor reconoce la posibilidad que tiene el enunciado de apoyar una conclusión pero esta no la agota, y en el segundo miembro presenta la conclusión contraria. Por ejemplo, en: "Aunque Juan venga, Pedro se quedará"7, se reconoce la potencialidad de que "Juan vendrá" como apto para apoyar la conclusión "Pedro no se quedará"; no obstante, se descarta y se impone la conclusión opuesta.

Además, Anscombre y Ducrot (1984) puntualizan que la concesión supone una "contraargumentación" (ANSCOMBRE y DUCROT, 1984), pues en ella se reconoce la validez del argumento presentado por aunque hacia una determinada conclusión, pero se concluye de modo contrario. De ahí deviene que aunque como conector contraargumentativo vincula "dos miembros del discurso de tal modo que el segundo se presenta como supresor o atenuador de alguna conclusión que se pudiera obtener del primero" (PORTOLÉS, 2007).

En lo que respecta a nuestro estudio, comprobamos que a través de las construcciones concesivas, el locutorautor suele presentar un discurso previo de un E1, que atribuye al destinatario-lector y al que admite como válido, pero al que inmediatamente descarta, pues E2 plantea una conclusión contraria. Por ejemplo, en (11), (12) y (13) se acepta la posibilidad de que el lector no crea en la veracidad de cierto saber científico: el E1 que emerge en (11) vehiculiza la siguiente idea: "parece extraño que la luz de la Luna no sea de ella"; en (12), "parece raro que los terremotos avancen mucho más rápido"; en (13), "cuesta creer que los hospitales no existan desde siempre ni fueran como son ahora". No obstante, se anula cada una de estas posibilidades y el segundo miembro vehiculiza el punto de vista de E2, que presenta la conclusión contraria en la medida en que se enuncia el dato empírico, opuesto a las creencias del sentido común expuestas por E1.

(11) Aunque te parezca extraño, la luz de la Luna no es de la Luna. ¿Y entonces de quién es? ¡Del Sol! (1:8)

(12) Aunque te parezca raro, avanzan mucho más rápido que tú. (10:37)

(13) Aunque te cueste creerlo, los hospitales no existen desde siempre ni fueron siempre como son ahora. $(6: 5)$

Los ejemplos revelan que las fórmulas concesivas aluden al lector mediante pronombres personales ("te") y el uso de verbos en modo subjuntivo en tiempo presente conjugados en segunda persona del singular que expresan la posible actitud del interlocutor ("parezca" o "cueste"). Por un lado, los verbos utilizados generalmente en este tipo de concesiones denotan acciones de creencia o parecer, y remiten a conocimientos previos adjudicados al destinatario-lector, o bien doxales. Por otro lado, el

\footnotetext{
7 Ejemplo presentado y analizado por Ducrot y Anscombre (1984).
} 
empleo del subjuntivo contribuye a expresar afirmaciones hipotéticas que plantean supuestas objeciones que podría realizar el destinatario-lector. De esta manera, la prótasis adelanta un posible rechazo o, al menos, la desconfianza del interlocutor ante el saber que se introduce en la apódosis. Así, mediante la fórmula concesiva con subjuntivo, el locutor-autor expresa una condición no suficiente y no acertada. Incluso, en (11) y (13), a través de la "negación polémica" (Ducrot, 1984), el locutor exhibe el discurso ajeno del E1 atribuido al destinatario-lector. Cabe recordar que, de acuerdo con Ducrot, la negación polémica opone los puntos de vista de enunciadores antagónicos. En este sentido, "estos enunciadores puestos en escena por el locutor son E1, punto de vista de la aserción rechazada y E2, enunciador del rechazo" (GARCÍA NEGRONI y TORDESILLAS COLADO, 2001, p. 205). En los ejemplos (11) y (13) se contraponen las perspectivas del sentido común y la científica: el punto de vista de E1 corresponde a un tipo de discurso doxal que es atribuido al lector ("la luz de la Luna es de la Luna" y "los hospitales existen desde siempre y fueron siempre como son ahora") y el punto de vista E2, con el cual se identifica el locutor-autor, corresponde al discurso científico y despliega el argumento contrario.

Al referirse al uso de las condicionales en el discurso académico, Hall y Marin (2011, p. 124) sostienen que puede suceder que el primer miembro del enunciado polemice con un discurso previo que no está presente en el enunciado, sino que se presuponga. Esto ocurre en el caso de las condicionales que aquí analizamos: el discurso previo no está presente en el enunciado sino que se presupone en el destinatario-lector, como un saber doxal o del sentido común.

Por otro lado, cabe destacar que Cravels (2000, mencionado en RODRÍGUEZ ROSIQUE, 2008) plantea que las cláusulas concesivas pueden alcanzar diferentes niveles de abstracción. Uno de ellos es el de "enunciación", en el que la prótasis se convierte en un obstáculo para la "ejecución" de la apódosis, pero que de todas formas se "realiza". El siguiente ejemplo, propuesto por Rodríguez Rosique, evidencia que el primer miembro remite a un argumento que corresponde al nivel de enuciación, pero que no invalida lo que se realice en la apódosis: "Aunque no es asunto mío, tu comportamiento es una vergüenza". Aquí, como explica Rodríguez Rosique (2008, p. 180): “A pesar de que P dificulta el 'acto de habla' de Q lo llevó a cabo".

El hecho de encontrar en nuestro corpus expresiones concesivas de este tipo demuestra que el foco de interés del sujeto divulgador se coloca, sin dudas, en el nivel de la enunciación. La concesión permite al locutorautor introducir marcos enunciativos desde donde la explicación se inicia y se contextualiza. De esta forma, el locutor-autor se muestra atento a las necesidades del lector lego, da cuenta de que conoce sus conocimientos pero también sus prejuicios, en la medida en que se adelanta ante una posible actitud de descreimiento o, incluso, de rechazo. Por un lado, se ocupa de atenuar el conflicto entre el conocimiento sensorial y el científico. Por otro lado, no considera al lector lego como una tabla rasa, sino que lo construye como un destinatario activo, con su bagaje de experiencias y saberes que emerge así como coconstructor del enunciado. Presentar y mostrar la alteridad de este modo implica que el divulgador tiene en cuenta una posible experiencia previa del destinatario; y frente a ella se posiciona.

Como es evidente, en la divulgación científica las estructuras concesivas ofrecen un marco enunciativo que introduce el discurso del sentido común y sirve como atenuador del conflicto entre el conocimiento sensorial y el conocimiento científico. La propiedad polifónica y contraargumentativa de las concesiones posibilita vehiculizar un punto de vista que, atribuido al destinatariolector, crea el efecto de sentido de que este es partícipe de la explicación.

\subsection{El imaginario de la construcción compartida del conocimiento. Proposiciones condicionales}

Otra de las características que presenta nuestro corpus es el predominio de construcciones condicionales con referencia explícita a la segunda persona del singular, y que suelen expresar correlación causal. En este sentido, hay que tener en cuenta que "las proposiciones condicionales expresan la condición de la que depende la realización de lo enunciado en la principal" (GARCÍA NEGRONI, 2010 , p. 359) y, según la relación de tiempos y modos, que se establece entre la prótasis y la apódosis pueden ser en "reales", "potenciales" o "irreales". No obstante, en los libros bajo análisis se hallan solo condicionales reales y potenciales.

Por un lado, en las reales "la condición no es una hipótesis, sino una evidencia o un hecho general a partir del cual se enuncia una consecuencia" (GARCÍA NEGRONI, 2010, p. 359). Por ende, la condición es exhibida como probable o realizable en el futuro.

En los casos que siguen (cf. 14 y 15), la prótasis condicional se formula en presente y la apódosis, en presente del modo indicativo. Como vemos, se enuncian conocimientos generales a partir de situaciones particulares en las que se involucra al destinatario-lector y, así, este queda incorporado en la explicación misma.

(14) Si andas por ahí y quieres ver la Luna, tan solo tienes que apuntar tus ojos arriba para atrapar parte de esa luz (antes de que llegue al suelo). (1:8). 
(15) Si hablas o ríes con la boca llena, la epiglotis se confunde. (4:53)

Pero también encontramos diversos ejemplos (cf. 16 y 17) en los que la prótasis condicional se enuncia en presente y la apódosis, en futuro del indicativo. En estos casos se suele inducir al destinatario-lector a la observación de un fenómeno con el fin de que corrobore su veracidad ("notarás", "vas a ver"). Lejos de configurarlo como un sujeto pasivo que solo recibe información, se lo construye a partir de la experiencia y la exploración, actividades, como sabemos, esenciales en la labor del científico-investigador.

(16) Si prestás atención, notarás que las nubes tienen una variedad de formas impresionantes $(5: 14)$

(17) Si parte de esta luz entra en tus ojos, vas a ver las gotas de agua que hay allá a lo lejos. (2:21)

Por otro lado, las condicionales potenciales se enuncian en subjuntivo, y su realización es menos probable o más hipotética que las reales. Como lo demuestra (18) la explicación se encuentra también centrada en el interlocutor lego y él la constituye. La exposición científica se formula, entonces, haciendo foco en el destinatario-lector, es decir que pone en evidencia la dimensión subjetiva del discurso.

(18) Si lo que estuvieras viendo pasar fuera una estrella amarilla, como está muy, muy lejos, no la escucharías; pero si verías que la luz cambia cuando se va acercando a vos: se ve azulada. Y cuando te deja atrás se ve rojiza. (8:7)

Según se corroboró en este apartado, el locutor-autor recurre a las proposiciones condicionales para apelar al destintario e incluirlo en acciones conjuntas. Se lo implica como observador, como explorador, incluso, como investigador, y así se borran solemnidades diluyendo el efecto de objetividad asignado tradicionalmente al discurso científico.

\section{A modo de conclusión}

Si bien todo discurso posee rasgos dialógicos (BAJTÍN, 1976 y 1982 y DUCROT, 1984), en la divulgación científica infantil escrita en español, estos se hacen manifiestos a partir del despliegue de diferentes mecanismos microdiscursivos. Con la pretensión evidente de amenizar y dinamizar los temas a desarrollar, así como de atenuar la distancia con el destinatario-lector, el locutor-autor configura la explicación como un diálogo explícito y manifiesto. A pesar de que inevitablemente la asimetría entre divulgador y lego se mantiene, pues el primero es quien posee el saber y regula la exposición, la decisión de mostrar la presencia del destinatario-lector, incorporarlo explícitamente en el texto y aludir a su imagen a través de la mención de sus posibles creencias, saberes y experiencias, tiene sus efectos de sentido. En efecto, lejos de presentar el discurso de la ciencia como objetivo y aséptico, los libros de divulgación aquí estudiados ponen en escena la alteridad y la dimensión subjetiva que lo constituyen.

El análisis ha revelado, así, que la exposición concebida como diálogo y centrada en el lector no solo puede hacer más sencilla la explicación, sino que la facilitaría, en la medida en los conceptos se presentan contextualizados y así el aprendizaje podría volverse realmente significativo. Entre los procedimientos microdiscursivos implementados para apelar al destinatariolector y cimentar el intercambio dialógico, hemos destacado tres tipos de alta ocurrencia: las preguntas con apelación directa al destinatario-lector y las marcas de coloquialidad; las construcciones concesivas y las proposiciones condicionales.

En primer lugar, se demostró que las preguntas con apelación al destinatario-lector contribuyen a la organización eficaz de la información, a la vez que permiten recuperar los conocimientos y las experiencias supuestas en el otro. Las preguntas, sumadas a las expresiones coloquiales, le quitan solemnidad a la explicación y ponen el acento en la dimensión emotiva y subjetiva del discurso. En segundo lugar, dimos cuenta de que las estructuras concesivas ofrecen un marco enunciativo que introduce el discurso del sentido común y funciona como un atenuador ante el posible conflicto entre el conocimiento sensorial y el conocimiento científico. En tercer lugar, a través de las proposiciones condicionales, el locutor-autor le adjudica al destinatario un rol activo y lo construye como observador y explorador, incluso como investigador. Todos estos procedimientos permiten modelar un ethos divulgador poseedor del saber pero que se exhibe atento al destinatario, es decir que si bien transmite conocimientos no se estanca en esa función, sino que se ocupa especialmente de facilitar la comprensión del texto. De manera simultánea, el locutor-autor proyecta la imagen de un destinatario-lector al que concibe como sujeto activo de conocimiento.

En suma, la divulgación científica destinada a niños se trata de un discurso en el que la subjetividad y la polifonía son puestas en escena. Los mecanismos abordados logran desplazar las características de objetividad y neutralidad adjudicadas comúnmente a la ciencia y ponen el foco en otra zona: en la dimensión subjetiva y lúdica que, como bien se sabe, constituyen la génesis de la actividad científica y son sus motores. 


\section{Referencias}

AMOSSY, Ruth (Dir.). Images de soi dans le discours. La construction de l'ethos. París: Delauchaux et Niestlé, 1999.

ANSCOMBRE, Jean-Claude; DUCROT, Oswald. L'argumentation dans la langue. Bruselas: Pierre Mardaga Éditeur, 1984.

BAJTÍN, Mijail. Problemas de la poética de Dostoievsky. Buenos Aires: Fondo de Cultura Económica, 1976.

BAJTÍN, Mijail. La estética de la creación verbal. México: Siglo XXI, 1982.

BENVENISTE, Emile. Problemas de lingüística general. México: Siglo XXI, 1966.

CALSAMIGLIA, Helena. Divulgar: itinerarios discursivos del saber. Una necesidad, un problema, un hecho. Quark, n. 7, p. 9-18, 1997.

CASSANY, Daniel. 1998. Análisis discursivo de la divulgación científica. Actas del I Simposio Internacional de Análisis del Discurso. Madrid: Universidad Complutense de Madrid. 1998. Disponible en: <http://www.upf.edu/pdi/dtf/daniel_cassany/>. Acceso el 25 de julio de 2015.

CASTRO FOX, Guillermina; MONTI, Claudia. Rasgos dialógicos en los libros de texto. Actas del I Congreso Argentino de la IADA. La Plata, 2003.

CIAPUSCIO, Guiomar. Impersonalidad y desagentivación en la divulgación científica, LEA, n. 14, p. 183-205, 1992.

CIAPUSCIO, Guiomar. Hacia una tipología del discurso especializado. Discurso y Sociedad, v. 2, n. 2, p. 39-71, 2000.

CIAPUSCIO, Guiomar. ¿"La Xylella fastidiosa" o "Xylella fastidiosa"?: las críticas metalingüísticas en las cartas de lectores de Ciencia Hoy. In: CIAPUSCIO, Guiomar (Ed.). Variedades del español de la Argentina: estudios textuales y de semántica léxica. Buenos Aires: Eudeba, 2013.

DUCROT, Oswald. El decir y lo dicho. Barcelona: Paidós, [1984] 2001.

FILINICH, Isabel. Enunciación. Buenos Aires: Eudeba, 1999. (Enciclopedia Semiológica).

GALLARDO, Susana. La presencia explícita del autor en textos académicos. RASAL, n. 2, p. 31-44, 2004.

GALLARDO, Susana. Las revistas de comunicación de la ciencia en la Argentina: propósitos comunicativos y niveles de especialidad. In: CIAPUSCIO, Guiomar (Ed.). Variedades del español de la Argentina: estudios textuales y de semántica léxica. Buenos Aires: Eudeba, 2013.

GARCÍA NEGRONI, María Marta. Subjetividad y discurso científico-académico. Acerca de algunas manifestaciones de la subjetividad en el artículo de investigación en español. Signos, v. 41, n. 66, p. 5-31, 2008.

GARCÍA NEGRONI, María Marta. Negación y descalificación: a propósito de la negación metalingüística. Ciências \& Letras, n. 45, p. $61-82,2009$.

GARCÍA NEGRONI, María Marta. Escribir en español. Claves para una corrección de estilo. Buenos Aires: Santiago Arcos, 2010

GARCÍA NEGRONI, María Marta (Coord.). Los discursos de la ciencia. Prácticas discursivas y enunciación académica. Buenos Aires: Editoras del Calderón.
GARCÍA NEGRONI, María Marta; RAMÍREZ GELBES, Silvia. Acerca del voseo en los manuales escolares argentinos (1970-2004). In: HUMMEL, M.; B. KLUGE; VÁZQUEZ LASLOP, M. E. (Eds.). Formas y fórmulas de tratamiento en el mundo hispánico. México: El Colegio de México, 2005. p. 1013-1032.

GARCÍA NEGRONI, María Marta; TORDESILLAS COLADO, Marta. La enunciación en la lengua. De la deixis a la polifonía. Gredos: Madrid, 2001.

HALL, Beatriz; MARÍN, Marta. El discurso académicopedagógico: complejidad discursiva. In: GARCÍA NEGRONI, María Marta (Coord.). Los discursos de la ciencia. Prácticas discursivas y enunciación académica. Buenos Aires: Editoras del Calderón, 2001. p. 101-131.

LÓPEZ, GARCÍA, María. La variedad geográfica en el género "manual escolar". Lectura y vida, n. 27, p. 42-50, 2006.

ORLANDI, Eni. Discurso e texto. Formulação e circulação dos sentidos. Pontes: Campinas, 2003.

PORTOLÉS, José. Marcadores del discurso. Barcelona: Ariel, 2007.

RODRÍGUEZ ROSIQUE, Susana. Pragmática y gramática. Condicionales concesivas en español. Frankfurt: Peter Lang, 2008.

TOSI, Carolina. Apelación al destinatario y exhibición de la subjetividad. Un análisis microdiscursivo de libros de texto argentinos. Logos - Revista de Lingüística, Filosofía y Literatura, v. 19, n. 2, 2009. Disponible en: <http://revistas. userena.cl/index.php/logos/article/view/16/12>. Acceso el: 25 jul. 2015.

TOSI, Carolina. Mitos y certezas en el discurso de la divulgación científica para chicos. Un análisis sobre la representación de la doxa y la reinterpretación de topoi. In: GARCÍA NEGRONI, María Marta (Coord.). Sujeto(s), alteridad y polifonía. Acerca de la subjetividad en el lenguaje y en el discurso. Buenos Aires: Ampersand, 2015a. p. 121-145.

TOSI, Carolina. La negación metadiscursiva en la divulgación científica para chicos. Actas de Aledar. Buenos Aires: Facultad de Filosofía y Letras, Universidad de Buenos Aires, 2015 b. (En prensa).

VALLEJOS, Patricia; PALMUCCI, Daniela. 2010. El alcance de la retórica en la divulgación científica infantil. In: Actas del I Coloquio Nacional de Retórica y I Jornadas Latinoamericanas de Investigación en Estudios Retóricos, Buenos Aires, 2010. p. 1299-1307.

VALLEJOS, Patricia; PALMUCCI, Daniela. 2011. Recursos de la divulgación científica en la literatura para niños. Construcción verbal y visual del disparate. Anclajes, v. XV, n. 2, p. 79-102, 2011.

\section{Libros citados del corpus}

1. BAREDES, Carla; LOTERSZTAIN, Ileana. La luz y los colores para los más curiosos. Buenos Aires: Iamiqué, 2014.

2. BAREDES, Carla; LOTERSZTAIN, Ileana. Preguntas que ponen los pelos de punta sobre la luz y los colores. Buenos Aires: Iamiqué, 2008. 
3. BOMBARA, Paula; BERNASCONI, Pablo. ¿Querés saber qué es el ADN? Buenos Aires: Eudeba, 2008.

4. BRANZEI, Sylvia. Asquerosología. Del cerebro a las tripas. Buenos Aires: Iamiqué, 2002.

5. CAMPOS, María Inés; COSARINSKY, Andrés. Sobre tormentas y tornados. Buenos Aires: Iamiqué, 2013.

6. DE AMBROSIO, Martín; LOTERSZTAIN, Ileana. La medicina no fue siempre así. Buenos Aires: Iamiqué, 2001.

7. FERNÁNDEZ, Natalia; FERNÁNDEZ ROLFI, Bana. ¿Querés saber qué son las Bacterias y los Virus? Buenos Aires: Eudeba, 2007.
8. GANGUI, Alejandro; BILLOTI, Viviana. ¿Querés saber qué es el Big Bang? Buenos Aires: Eudeba, 2008.

9. GANGUI, Alejandro; BILLOTI, Viviana. ¿Querés saber qué son las estrellas? Buenos Aires: Eudeba, 2008.

10. SIMONOTTI, Fernando; BABY, Gabriela. Terremotos y volcanes para los más curiosos. Buenos Aires: Iamiqué, 2014.

Recebido: 26 de setembro de 2015.

Aprovado: 28 de outubro de 2015.

Contato: carolinaltosi@gmail.com 